\title{
Treatment and valorization of olive mill wastewaters
}

\author{
Nabila Slimani Alaoui *, Anas El Laghdach, Mostafa Stitou and Aniss Bakkali \\ Laboratory of Water ,Studies and Environmental Analysis, Department of chemistry, Faculty of Sciences, \\ University Abdelmalek Essaâdi, B.P. 2121, Mhannech II, 93002 Tetouan, Morocco.
}

\begin{abstract}
This study aims to evaluate the effectiveness of the physicochemical process with lime and ferric chloride in removing the pollution generated by the olive mill wastewaters (OMW). The characterization of the samples has shown that they are acidic, with a black color and a strong organic load due to the presence of phenolic compounds. The combination of the lime and the ferric chloride allows the removal of $87 \%$ of the total suspended solid (TSs), 58\% of chemical oxygen demand (COD) and 75\% of Phenolic compounds. After purification the treated OMW were valorized as wash water or used for irrigation of green spaces and the generated sludge were dried and used as burning material.
\end{abstract}

Keywords: OMW, Characterization, Physicochemical Treatment, Valorization.

\section{Introduction}

The olive tree is the main fruit planted in Morocco, it occupies more than $58 \%$ of the national tree area $^{1}$, the production is estimated at 1.500 .000 tons of olives on an area of 933.475 hectares, a figure that the kingdom aims doubling in $2020^{2}$. In terms of production Morocco ranks the fifth place in the world after Spain, Italy, Tunisia, and Greece ${ }^{3}$.

Since ancient times the oil was traditionally obtained by pressure until the introduction of the centrifugation in olive mills. In the late 80 s in Spain, after a severe drought and a big increase in production, the extraction of olive oil was obtained by the continuous extraction system including a vertical and horizontal centrifugation which separates the olive mixture in three-phase: oil, pomace and a black liquid effluent called olive mill wastewaters (OMW) or in two phases: oil and wet pomace. The two-phase system uses a small amount of water and therefore a lower dissolution of phenolic compounds remains in the oil, but who also make it bitter ${ }^{4-5}$.

The olive mill wastewaters generated from olive oil extraction causes a major environmental issue when they are directly discharged into rivers, they greatly change the quality of surface waters and produce serious environmental damages and disrupt the operation of treatment plants when they come through the sewers. The annual production of this effluent exceeds 30 million $\mathrm{m}^{3}$ per year; pressing $1 \mathrm{Kg}$ of olives can generate $0.5-1 \mathrm{~L}$ of OMW with modern production modes ${ }^{6-7}$.
The problem of disposing of OMW was apprehended in different ways by the Mediterranean olive-growing countries, which have adopted point solutions to solve this problem. The difficulty of treatment of these effluents is due to their poor biodegradability due to the presence of phenolic compounds $^{8-9}$, lipids and organic acids.

Taking into account the composition and the toxicity degree of the OMW, simple treatments are not sufficient to ensure their purification. Some biological (with aerobic and anaerobic microorganisms) ${ }^{10,11}$, chemical ${ }^{12}$ and physical ${ }^{13}$ treatments have been applied and have proved to be effective for reduction of the organic content of OMW. Many solutions of valorization were adopted to prevent the environmental pollution. The OMW is proposed as a renewable resource to produce valuable photochemical compounds, to extract natural chemicals or to be used as fertilizers ${ }^{14,15}$.

This work aims to provide an effective treatment valid for the different olive extraction systems, able to reduce or even eliminate the organic matter contained in the OMW. The treatment proposed is the physicochemical treatment using the lime and the ferric chloride followed by a decolourization and desinfection with chlorine. The capacity of removing the phenolic compounds, COD and total suspended solids will be evaluated

The capacity of removing the phenolic compounds, COD and total suspended solids will be evaluated, in addition to the valorization of the treated OMW and recycling the sludge generated.

Received Mars $2^{\text {nd }}, 2016$

Accepted April 5 th $^{\text {t }} 2016$

Published April $23^{\text {rd }}, 2016$ 


\section{Experimental Section \\ Sampling}

The samples of OMW studied were obtained from a three phase olive oil extraction unit located in the city of Meknes. The OMW were collected every day from the storage tank which gathers all the OMW produced in the industry, namely: Washing water, OMW generated after extraction and the rainwater. Samples were analyzed in the laboratory of the unit.

\section{Physical-chemical analysis of OMW}

The color measurement is done using a rotating disk apparatus (Lovibond Comparator 2000+); the color of the OMW was compared to the discs with different colors from white to brown. Once the colors is close the corresponding value given in Hazen is taken by taking into account the dilutions.

The $\mathrm{pH}$ of the samples was continuously measured using a $\mathrm{pH}$ meter $(\mathrm{pH}$ 1100) Eutech instruments $\mathrm{pH} / \mathrm{mV} /{ }^{\circ} \mathrm{C}$.

Fats were extracted from the OMW by Hexane; the mixture was evaporated in a rotary evaporator (Nahita, Rotary Evaporator 9200 ) at $80^{\circ} \mathrm{C}$. Fats were calculated by weight difference.

The total solid (TS) was determined by weighting the samples before and after drying at $105^{\circ} \mathrm{C}$ for $24 \mathrm{~h}$.

The total suspended solid (TSs) was determined after filtering a sample through a filter $(0.45 \mu \mathrm{m})$ using vacuum pump and drying the filtrate obtained at $105^{\circ} \mathrm{C}$ for $24 \mathrm{~h}$.

The mineral matter (MM) was measured after calcination of the OMW in an oven at $600^{\circ} \mathrm{C}$ for $4 \mathrm{~h}$. The biological oxygen demand $\left(\mathrm{BOD}_{5}\right)$ is the amount of oxygen required to oxidize biologically the organic matter contained in the OMW. The samples of OMW were diluted and introduced in $\mathrm{DOB}_{5}$ bottles (OxiTop IS6) containing a bar magnetic, they were then placed in a thermo cupboard at $20^{\circ} \mathrm{C}$. After 5 days of incubation the value of $\mathrm{BOD}_{5}$ was measured taking into account the dilution factor.

The biochemical oxygen demand is an oxidation of organic matter by excess of potassium dichromate. COD of the OMW was calculated from the volume of salt Mohr used for titration of Mohr's salt.

Polyphenols are a family of organic molecules widely present in the OMW they were assayed by colorimetric method using tannic acid as a standard at $725 \mathrm{~nm}$.

All parameters were analyzed in triplicate, and determined following standard methods ${ }^{16-17}$

\section{Treatment by Coagulation-Flocculation}

The Physico-chemical treatment by coagulationflocculation is based on the addition of a reagent to the mixture to be treated, in order to destabilize the fine suspended matter by reducing electrostatic repulsion forces ${ }^{18-19}$.

In this work the physicochemical treatment by coagulation flocculation is based on the use of lime and ferric chloride.

Samples of OMW were allowed to stand for 1hour until the suspended matter has settled.

In a series of $100 \mathrm{~mL}$ beakers, raw OMW were used without adjusting $\mathrm{pH}(\mathrm{pH}=4.6)$ and we followed this protocol:

- Increasing doses of lime (Purity>92\%) were added (1.5-7.5)g/L on raw OMW to adjust the acidic $\mathrm{pH}(\mathrm{pH}=4.6)$ to a $\mathrm{pH}$ widely basic $(\mathrm{pH}=$ 10) ;

- The mixture was agitated with rapid magnetic stirring for $3 \mathrm{~min}$ at $180 \mathrm{rpm}$ followed by slow mix for $30 \mathrm{~min}$ at $30 \mathrm{rpm}$;

- The ferric chloride $\left(\mathrm{FeCl}_{3}, 41 \%\right)$ was then added $(0.5-1.5) \mathrm{g} / \mathrm{L}$ on the supernatants recovered after treatment with lime and the mixture was agitated again by rapid magnetic stirring $3 \mathrm{~min}$ at $180 \mathrm{rpm}$ followed by a slow mix for $30 \mathrm{~min}$ at $30 \mathrm{rpm}$;

- The mixture must be decanted at least 5 hours to separate the liquid phase from the particulate phase;

- After decantation the mixture was filtered over a filter paper (100 mm) using a vacuum pump.

\section{Reuse of treated OMW}

When we need to reuse the treated OMW, $200 \mathrm{ml} / \mathrm{L}$ of bleach can be added the filtrate obtained. It allowed the disinfection and the decolourization of the OMW.

\section{Sludge Treatment}

The physicochemical treatment generates sludge during the various processing steps. The sludge were collected after clarification and dried in an oven for $4 \mathrm{~h}$ at $105^{\circ} \mathrm{C}$. 


\section{Results and Discussion}

\section{Characterization of the OMW}

The characteristics of the studied raw OMW are summarized in the following Table:

Table 1. Characteristics of OMW produced in a three phase continuous extraction unit

\begin{tabular}{|cc|}
\hline Parameters & Values \\
\hline pH & $4.5-5$ \\
\hline $\begin{array}{c}\text { Conductivity } \\
\text { (mS/cm) }\end{array}$ & 14 \\
\hline Color & Brown-Black \\
\hline Fats & 0.6 \\
\hline $\begin{array}{c}\text { Total suspended } \\
\text { solid (TSs) (g/L) }\end{array}$ & 14.8 \\
\hline $\begin{array}{c}\text { Total solid } \\
\text { (TS)(g/L) }\end{array}$ & 23.9 \\
\hline $\begin{array}{c}\text { Mineral matter } \\
\text { (MM)(g/L) }\end{array}$ & 4.96 \\
\hline BOD (g O) /L) & 45 \\
\hline COD $(\mathbf{g ~ O}$ /L) & 64 \\
\hline Total phenols $(\mathbf{g} / \mathbf{L})$ & 2.1 \\
\hline
\end{tabular}

The characterization of the studied samples shows an acidic $\mathrm{pH}$. This low value indicates that the use of this effluent for irrigation can damages soil ${ }^{20}$, except calcareous soils where the equilibrium can be established (e.g. of the city of Meknes). The conductivity $(14 \mathrm{mS} / \mathrm{cm})$ is high compared to other studies, this is essentially due to the significant addition of salt to preserve the olives ${ }^{21-22}$. The OMW are brown to brown-blackish, the color intensifies with the storage time and the oxidation of phenolic compounds ${ }^{23}$. In our case these molecules are present in low content in comparison with results reported by S. Azabou et $a l^{24}$. The OMW are rich in TSs which may be due to bad separation of OMW from the olive pomace. In our case the content of fats is much lower compared to that reported in the literature ${ }^{25}$, the OMW studied were collected from a storage tank which allowed the removing of the excess of suspended matter and fats.

The ratio $\mathrm{BOD}_{5} / \mathrm{COD}$ indicates the biodegradability of waste water. Industrial wastewaters which have a ratio higher than 0.3 are easily biodegradable ${ }^{26}$, in our case the biological treatment can be applied but it will be limited by the presence of phenolic compounds which inhibits the microbial activity ${ }^{27}$.

\section{Treatment of the OMW by Coagulation-}

\section{Flocculation}

The OMW are unstable in the same day which requires the use of a treatment highly adaptable to changes to the effluent.

After a simple decantation, $15 \%$ of TSs was eliminated without affecting the $\mathrm{pH}$. The addition of the lime $(7.5 \mathrm{~g} / \mathrm{L})$ allowed the adjustment of the acidic $\mathrm{pH}$ (4.6) to a basic $\mathrm{pH}(10)$. Burnt lime $(\mathrm{CaO})$ is often used for water treatment for its avaibility and effectiveness The neutralization by lime leads the transformation of phenols to phenates with the formation of $\mathrm{C}_{6} \mathrm{H}_{5} \mathrm{O}^{-}$ions ${ }^{28}$ (Fig 1), the phenolic compounds obtained lose much of their antibacterial effect and biological activity can therefore start ${ }^{29-}$ ${ }^{30}$.The percentage of elimination of polyphenols with lime attain $68 \%$, similar results were reported by E. S. Aktas and al where they shows that the precipitation with lime allowed the elimination of $65 \%$ of Polyphenols and only $28 \%$ of volatile phenols, the phenolic substances could be removed totally or partially and some of them were not affected ${ }^{31}$.

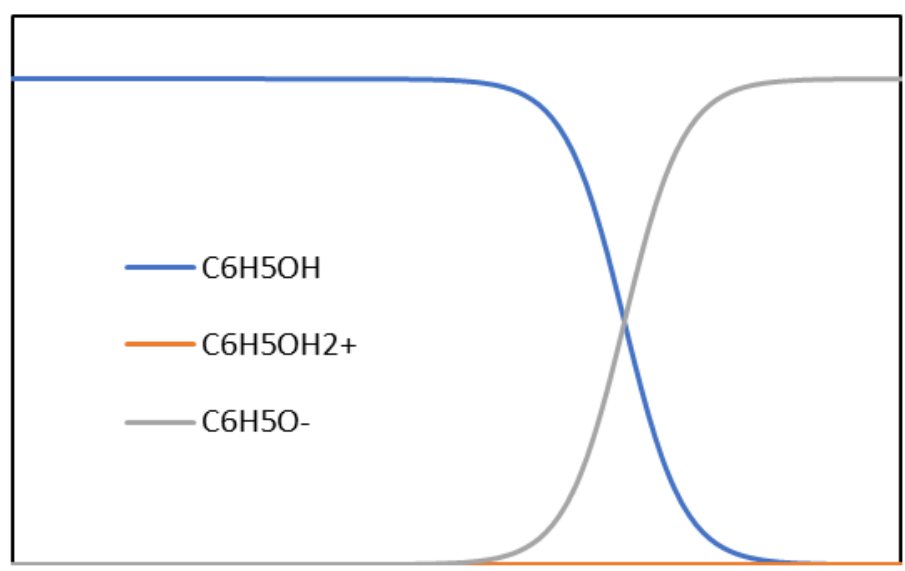

Figure 1. Different forms of phenol in different $\mathrm{pH}$

Lime allowed the removal of $57 \%$ of TSs and $41 \%$ of COD. The treatment with lime removes suspended matter, grease and oils which causes the reduction of the COD and forms large aggregations of floc ${ }^{32}$. Figure 2 represents the evolution of the different parameters of OMW after treatment with lime. 


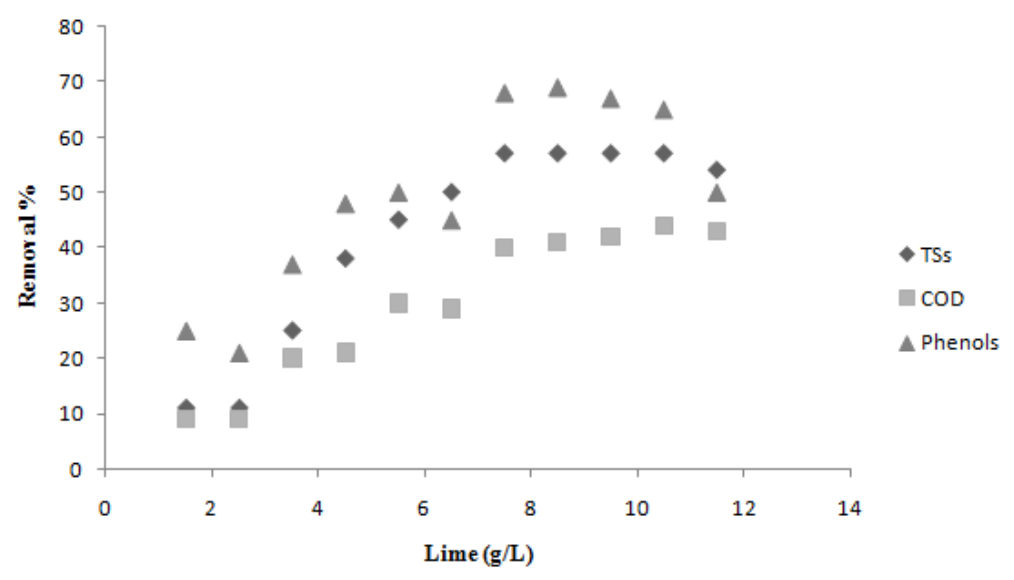

Figure 2. Evolution of TSs, COD and Phenols after treatment with lime

Flocculants are always used at low dosage $(0.5$ to $2 \mathrm{~g} / \mathrm{L}$ ) to complete the initial coagulation of colloids provided by liming. The addition of ferric chloride as a flocculent allows the removal of organic matter present in the OMW ${ }^{33}$. It provides a good flocculation of the particles contained in the OMW and promotes the removing of phosphates coming from fertilizers or agricultural activities ${ }^{34}$. Ferric chloride allows also the elimination of fats which remains in the OMW after decantation and liming. The Percentage of removal of TSs, COD and polyphenols is respectively $87 \%, 58 \%$ and $75 \%$. The ferric chloride allows the passage of the dissolved form of pollutants to an insoluble particulate form which can be easily retained by simple decantation and gives settleable floc ${ }^{30,35}$. Figure 3 summarizes the evolution of the characteristics of OMW after treatment with lime and ferric chloride.

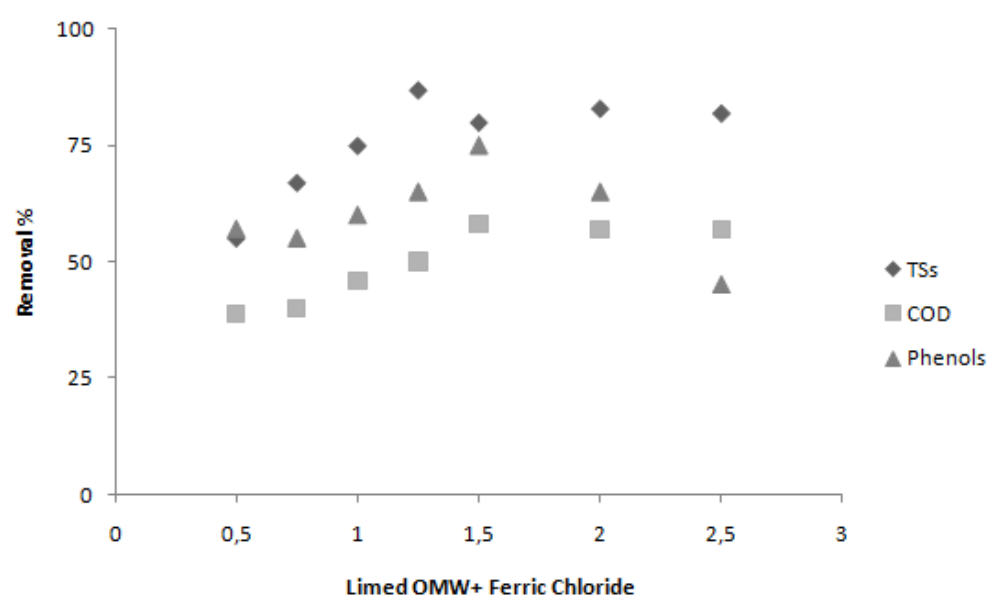

Figure 3. Evolution of TSs, COD and Phenols after treatment with lime and ferric chloride

The clarification of the treated OMW for at least 5 hours is necessary it allowed the separation of the liquid phase of the colloids and hydroxide floc which agglomerate after treatment with ferric chloride ${ }^{36}$. Figure 4 summarizes the steps performed for the removal of organic matter from raw OMW obtained from the three phase extraction.

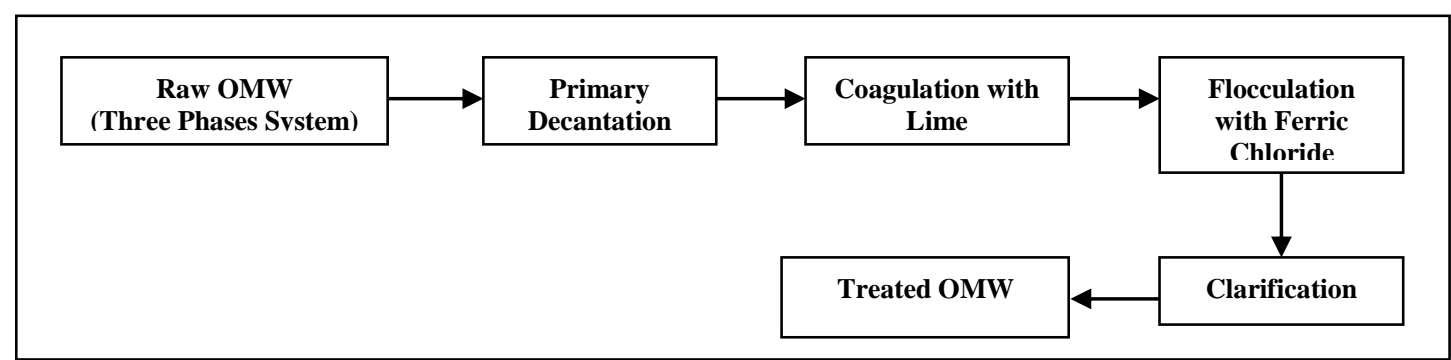

Figure 4. Steps performed for the removal of organic matter from raw OMW 


\section{Reuse of treated $\mathrm{OM}$}

The chlorination (Post-chlorination) is an optional step which can be added when we want to reuse the treated OMW as water wash .Chlorine ensures the disinfection and decolourization of the effluent, the neutralization of the $\mathrm{pH}(\mathrm{pH}=7)$ and the removal of organic impurities which are not retained after clarification ${ }^{35}$. The percentage of COD and decolourization reach respectively $65 \%$ and $71 \%$. The treated OMW remain on their same condition when they are exposed to light or stored which explains that the majority of phenolic compounds, especially responsible of coloration, were removed.

In our case after chlorination and secondary decantation we proposed the reuse of the treated OMW as wash water or for irrigation.

Some tests were performed on raw OMW to evaluate the effectiveness of the physicochemical treatment by coagulation-flocculation followed by chlorination. Figure 5 includes the treatments used only for decolourization of OMW.

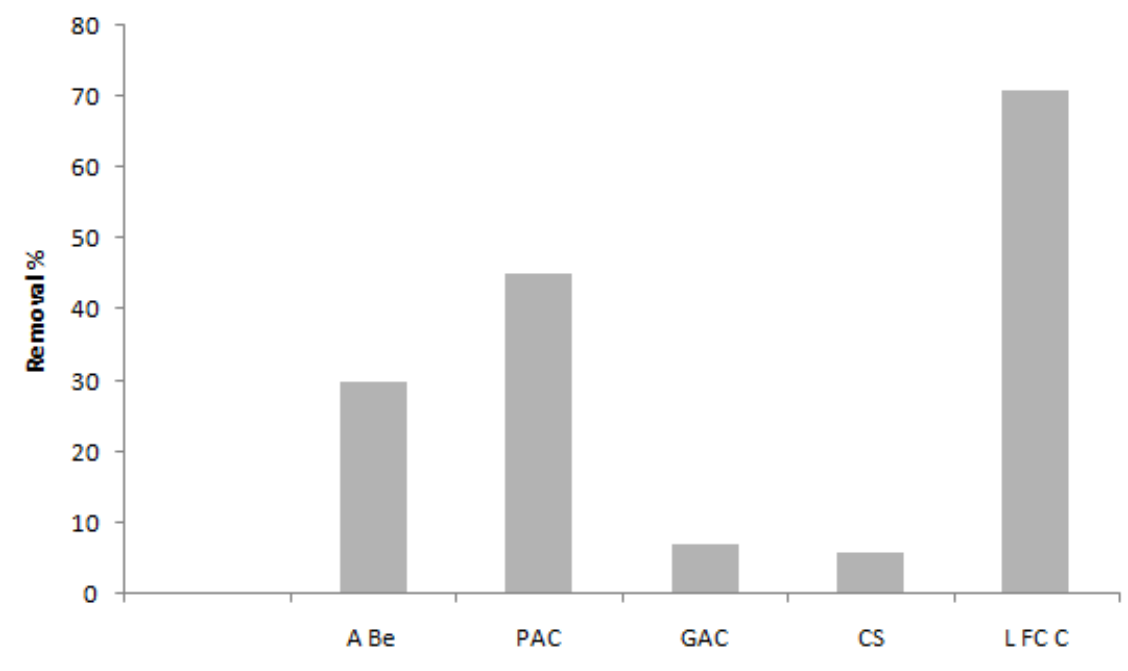

Figure 5. Treatments tested for Discoloration of the raw OMW

A Be: Adsorption with Activated Bentonite, PAC: Powder Activated Carbon, GAC: Granular Activated Carbon, CS: charcoal stick, LFC C: Lime+Ferric C +Chlorine

In our study the physicochemical treatment by coagulation-flocculation using lime and ferric chloride followed by chlorination after clarification gave the best discoloration of raw OMW with a removal percentage reaching $71 \%$.

\section{Sludge treatment}

The disadvantage of the physico-chemical treatment by coagulation-flocculation is the production of large amounts of sludge and the difficulty of regeneration of reagents, which increase the cost of processing and generates another source of pollution.

In our study we solved the problem of sludge at the factory as follows:

- The primary decantation produces a fresh sludge, it represents $20 \%$ of the volume (depends on the retention time) and it usually mixed with the wet pomace.

- The sludge generated from the treatment with lime (limed sludge) is conform to legislation; they are often highly valued by farmers due to their economic interest ${ }^{32}$. This sludge can neutralize the acidic sludge generated after treatment with ferric chloride.

- The sludge generated after clarification are acid too on which the burnt lime or limed sludge can be added to adjust the $\mathrm{pH}$. After drying in for 4 hours, the dried sludge is recovered in the form of coal and used for combustion.

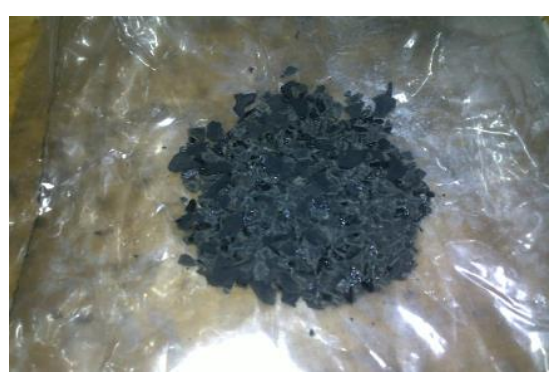

Picture 1. Dried sludge

\section{Conclusion}

Samples of raw OMW were collected from a three-phase olive mill to determine the pollutant responsible of their toxicity. The characterization shows that they are acidic, rich in organic matter and phenolic compounds which limits their biodegradation. The treatment of the OMW by coagulation flocculation with lime and ferric chloride allowed a destabilization of colloidal particles and a transformation of the phenolic compounds, which facilitated the agglomeration of the hydroxide floc by simple decantation. Chlorination must be used 
when a reuse of the treated OMW is planned; it ensures the disinfection and decolourization of the effluent. The sludge generated after clarification was dried and used as burning material.

\section{References}

1- B. Boulouha, L'amélioration génétique de l'olivier au Maroc programme prometteur pour le développement de l'oléiculture nationale ; Bulletin trimestriel de l'INRA : Marrakech, 2007, Vol.2, $\mathrm{N}^{\circ} 01$.

http://www.inra.org.ma/docs/119052009163829. pdf.

2- Ministère d'agriculture et de la pêche maritime, Veille économique-Secteur oléicole, Maroc, 2013, Note stratégique $\mathrm{N}^{\circ} 95$.

3- I. El Mouhtadi, M. Agouzzal, F. Guy, L'olivier au Maroc. OCL : Oléagineux, Corps Gras, Lipides, 2014, 21(2), pp.1-3. http://www.ocljournal.org/articles/ocl/pdf/2014/02/ocl130034. pdf.

4- H. Chimi, Technologies d'extraction de l'huile d'olive et gestion de sa qualité ; Bulletin mensuel d'information et de liaison de PNTTA : Maroc, 2006, $\mathrm{N}^{\circ} 141$, pp.1-4.

5- Agro-pôle Olivier et Agence d'Exécution du Projet CFC/IOOC/04, Les bonnes pratiques d'épandage des margines et du compost sur les terres agricoles: Cas de l'olivier: Meknes, 2004, pp.1-17.

6- C. Pintucci et $a l$, Fresh olive mill waste deprived from polyphenols as feedstock for hydrogen photo-production by means Rhodopseudomonas palustris 42OL, Renew. Energy, 2013, 51, 358363.

7- N. Benyahia and K. Zein, Analyse des problèmes de l'industrie de l'huile d'olive et solutions récemment développées ; Sustainable Business Associates : Lausanne 2003, pp.1-8.

8- I. Ntaikou et al, Exploitation of olive oil mill wastewater for combined biohydrogen and biopolymers production, Bioresour. Technol, 2009,100, 3724-3730. doi: 10.1016/j.biortech.2008.12.001

9- K. Baransi, Y.Dubowski, I.Sabbah, Synergetic effect between photocatalytic degradation and adsorption processes on the removal of phenolic compounds from olive mill wastewater, Water Res, 2012, 46, pp.789-798. http://www.ildesal.org.il/pdf/gwri_abstracts/2012 1/14.pdf.

10- S.E. Garrido Hoyos, L. Martinez Nieto, F. Camacho Rubio, Ramos Cormenzana, Kinetics of aerobic treatment of olive-mill wastewater (OMW) with Aspergillus terreus, Process Biochem, 2002, 37, pp.1169-1176. doi: $\underline{10.1016 / \mathrm{S} 0032-9592(01) 00332-6}$
Despite these satisfactory results physicochemical treatment by coagulation flocculation remains an expensive treatment, responsible for another source of pollution, which can be applied as a pre-treatment or secondary treatment.

11-M.R. Gonçalves, J.C. Costa, I.P. Marques, M.M. Alves, Strategies for lipids and phenolics degradation in the anaerobic treatment of olive mill wastewater, Water Res, 2012, 46, pp.16841692. doi: 10.1016/j.watres.2011.12.046

12- H.El Hajjouji et al, Photochemical UV/TiO2 treatment of olive mill wastewater (OMW), Bioresour.Technol, 2008, 99, pp.7264-7269. https://core.ac.uk/download/files/437/12041824. pdf.

13- M.Achak, N.Ouazzani,L.Mandi, Traitement des margines d'une huilerie moderne par infiltrationpercolation sur un filtre à sable, Rev. Des Sci. L'eau, 2009, 22(3), pp. 421-433.

14- A. Nefzaoui, Valorisation des sous-produits de l'olivier, Options méditerranéens. 1991, 16, pp. 101-108.

15- A.Ouatmane, V.Dorazio, M. Hafidi, J.C.Revel, N.Senesi, Elemental and spectroscopic characterization of humic acids fractionated by gel permeation chromatography, Agronomie, 2000, 20, pp.491-504.

16- J. Rodier, L'analyse de l'eau : Eaux naturelles, eaux résiduaires, eaux de mer ; Dunod, ISBN: 2-04-010045-8, 1978, 160-193.

17- J. Rodier, L. Bernard and M. Nicole, L'Analyse de l'eau: Eaux Naturelles, Eaux Résiduaires, Eau de Mer. 8th ed.by Dunod, DL, Paris, 2005, ISBN: 2100496360, pp: 1383.

18- A. Jaouani, M. Vanthournhout, M.J. Penninckx, Olive oil mill wastewater purification by combination of coagulation-flocculation and biological treatments,Environmental Technology, 2005, 26, pp. 633-641

19- P. Mouchet, Traitement des eaux avant utilisation, Substances dissoutes, Techniques de l'ingénieur traité Environnement : Strasbourg, 2000, ISSN : 1282-9080.

20- A. Nefzaoui, Contribution à la rentabilité de l'oléiculture par une valorisation optimale des sous-produits, Options méditerranéens. 1991, pp. 153-173.

21- M. Achak, A. Hafidi, N. Ouazzani, S.Sayadi, L. Mandi ,Low Cost Biosorbent "Banana Peel” for the Removal of Phenolic Compounds from Olive Mill Wastewater: Kinetic and Equilibrium Studies, J. Hazard. Mater, 2009, 166, pp 117-125.

22- F.Aouidi, H.Gannoun, N.Ben Othman, L.Ayed, M.Hamdi, Improvement of fermentative decolorization of olive mill wastewater byLactobacillus paracasei by cheese whey's addition, Process Biochem, 2009, 44, pp. 597- 601. 
23- S.Khoufi, F.Feki, S.Sayadi, Detoxification of olive mill wastewater by electrocoagulation and sedimentation processes. J. Hazard. Mater, 2007, 142, pp.58- 67.

24- S.Azabou, W.Najjar, A.Gargoubi, A.Ghorbel, S.Sayadi, Catalytic wet peroxide photo-oxidation of phenolic olive oil mill wastewater contaminants. Part II.Degradation and detoxification of low-molecular mass phenolic compounds in model and real effluent, Appl. Cat. B: Environ, 2007, 77, pp.166-174.

25- A. Ben Sassi, A. Boularbah, A. Jaouad, G.Walker, A. Boussaid, A comparison of olive oil mill wastewaters (OMW) from three different processes in Morocco, Process Biochem, 41,2006,pp.74-78

26- J. Boeglin, Propriétés des eaux naturelles. Techniques de l'Ingénieur, traité Environnement: Nancy, 2001, ISSN : 1776-0135, G1250.

27- F.Caponino, M.T.Bilancia, A.Pasqualone, E.Sikorska, T.Gomes, Influence of the exposure to light on extra virgin olive oil quality during storage, Eur. Food. Res. Technol, 2005, 221, pp. 92-98.

28- J.J.Macheix, A. Fleuriet and J.A. Billo, Fruit phenolics, Boca Raton Florida: CRC Press Inc, 1990, pp. 378.

29- F. Medeci, C.Merli, E. Spagnoli, Anaerobic digestion of olive mill wastewater: a new process. H.In Ferranti, M.P.Ferrero, H.Vaveau, Eds, Anaerobic digestion and carbohydrates hydrolysis of waste;Elsevier : London, 1985, pp. 385-398.
30- A. Yaakoubi, A. Chahlaoui, M. Rahmani, M. Elyachioui, Y. Oulhote, Effet de l'épandage des margines sur la microflore du sol, Agro solutions, 2010, 20 (1), pp. 35-43.

http://www.irda.qc.ca/assets/documents/Publicati ons/documents/yaakoubi-et-al 2009_article_effet_epandage_margines_microflo re_sol.pdf.

31- E. S. Aktas, S. Imre and L. Ersoy, Characterization and lime treatment of olive mill wastewater, Wat. Res, 2001, 35(9), pp. 2336-2340. PII: S0043-1354(00)00490-5

32- G. Lolos, A. Skordilis \& G. Parissakis, Polluting characteristics and lime precipitation of olive mill wastewater. Journal of Environmental Science \& Health Part A, 1994, 29, 7, pp. $1349-1356$. http://dx.doi.org/10.1080/10934529409376115

33- P. Mouchet, Traitement des eaux avant utilisation : Matières particulaires, Traité Environnement, 2000, G1, G1172.

34- L. Sigg, P.Behra, W. Stumm, Chimie des milieux aquatiques - Chimie des eaux naturelles et des interfaces dans l'environnement, $5^{\text {ème }}$ ed Dunod : Paris, 2000, pp. 547. http://www.unitheque.com/UploadFile/Documen tPDF/C/H/IKMG-9782100588015.pdf.

35- J. Boeglin, Traitements physico-chimiques de la pollution soluble, Techniques de l'Ingénieur, traité Environnement: Nancy, 2001, G1271.

36- J. Boeglin, Pollution industrielle de l'eau, Stratégie et méthodologie, Techniques de l'Ingénieur, traité Environnement: Nancy, 1998, G1220. 